\title{
Evidence for impaired insulin production and higher sensitivity in stunted children living in slums
}

\author{
P. A. Martins* and A. L. Sawaya \\ Department of Physiology, Federal University of São Paulo, São Paulo, Brazil \\ (Received 28 April 2005 - Revised 6 January 2006 - Accepted 16 January 2006)
}

\begin{abstract}
The objective of the present study was to investigate the changes in glucose and insulin metabolism in nutritionally stunted children that can be involved in the appearance of chronic diseases in adulthood. For this purpose, sixty-one children were selected, thirty-five boys and twenty-six girls, residents of slums in São Paulo, Brazil. The children were classified according to the height-for-age as stunted ( $\leq-1.5 Z$-score; $n$ 21) or non-stunted ( $>-1.5 Z$-score; $n 40)$. The glucose and insulin plasma levels were determined and, from these values, the indexes that evaluate the pancreatic $\beta$-cell function (homeostasis model assessment (HOMA-B)) and insulin sensitivity (HOMA-S) were assessed. Stunted children showed lower values of fasting insulin than those of the non-stunted group (boys: 29.7 (SD 14.9) v. 50.4 (SD 29.2) pmol/l, $P=0.019$; girls: 34.4 (SD 12.6) v. 62.3 (SD 28.7) pmol/l, $P=0.016$ ) but the glucose levels were similar (boys: 4.6 (SD 0.3 ) v. 4.5 (SD 0.3 ) mmol/l; girls: 4.2 (SD 0.3) v. 4.4 (SD 0.3) mmol/l). Stunted children showed lower HOMA-B values (boys: 83 (SD 22) \% v. 115 (SD 36) $\%, P=0.011$; girls: 107 (SD 23) \% v. 144 (SD 46) \%, $P=0.045$ ) and higher HOMA-S values (boys: 196 (SD 92) \% v. 120 (SD 62) \%, $P=0.014$; girls: 159 (SD 67) \% v. 98 (SD 57) \%, $P=0.016$ ). The results show a decreased activity of $\beta$-cell function and increased insulin sensitivity in stunted children. The decreased $\beta$-cell function of this group may strongly predict type 2 diabetes.
\end{abstract}

Stunting: Undernutrition: Insulin sensitivity: $\beta$-Cell function: HOMA

Previous studies on nutritionally stunted children living in the slums of São Paulo and, therefore, living in extreme poverty, showed a lower fasting RQ when compared with non-stunted children of the same age, indicating a tendency to preserve adipose tissue stores (Hoffman et al. 2000c). Their finding was confirmed when these children were re-evaluated 3 years later and a gain of fat mass as opposed to lean mass was observed in comparison with non-stunted children, showing a tendency towards overweight and obesity (Martins et al. 2004). Other metabolic changes were also observed in these and other stunted children in the same communities, such as a decrease in energy expenditure (Hoffman et al. 2000c; Grillo et al. 2005), impaired regulation of food intake (Hoffman et al. 2000a) and an increase in arterial hypertension (Fernandes et al. 2003).

Recently, Florêncio et al. (2001), studying the residents of slums on the outskirts of Maceió-Alagoas, demonstrated a high prevalence of overweight/obesity $(30 \%)$ in stunted women. This condition was verified even with an energy intake of only $65 \%$ of the required intake adjusted to stature (Florêncio et al. 2003). An association between stunting and arterial hypertension was also observed and this association was even more evident in women who presented a higher content of abdominal fat (Florêncio et al. 2004).

Studies carried out on individuals after prenatal exposure to famine during the Second World War found glucose intolerance (Ravelli et al. 1998). Although the prevalence of type 2 diabetes in individuals that were undernourished in early life is not known, it is known that poor countries with an accelerated urbanization process are particularly vulnerable and have been experiencing a considerable increase in the prevalence of type 2 diabetes (Yajnik, 2004).

Classic studies involving hospitalized, severely undernourished children observed lower fasting insulin levels and hypoglycaemia, rising during recovery and peaking during the phase of rapid growth. A subnormal insulin response to a glucose load, which frequently persisted for many months after recovery, was also described in those children (Waterlow, 1992).

According to our knowledge no studies have been done that relate the increased susceptibility to fat gain and the metabolism of glucose and insulin in stunted children.

The objective of the present study was therefore to verify if the children living in slums and who are stunted because of chronic undernutrition during infancy show changes in production and sensitivity to insulin, which could lead to type 2 diabetes in adult life, and/or facilitate body fat gain.

\begin{abstract}
Methods
Protocol

Sixty children were randomly selected among the 400 children screened in an anthropometric census performed in three slums in the south area of the city of São Paulo to participate in a cross-sectional study (Hoffman et al. 2000a,b,c) and after a period of 3 years, fifty-three of these children were located,
\end{abstract}


twenty-seven boys and twenty-six girls, to participate in a second phase analysis whose details were described elsewhere (Martins et al. 2004). The slums were randomly selected from among all the slums that are within $50 \mathrm{~km}$ of the Federal University of São Paulo, where the study was conducted. The present results represent the evaluation of the second phase of the study, therefore being cross-sectional.

The children were divided into two groups according to their height-for-age: the stunted group (height-for-age $\leq-1.5 Z$-score, $n 21$ ) and the non-stunted group (heightfor-age $>-1.5 Z$-score, $n$ 32). In addition, eight non-stunted boys of the same age, recruited from the same population to participate in another study, were included in the analysis to eliminate differences in pubertal stage between groups.

The children were brought to the university in the morning for the anthropometric and clinical evaluations and collection of a fasting blood sample $(20 \mathrm{ml})$ for the biochemical analyses. Before the experimental protocol began, preliminary blood, faecal and urine tests were performed to ensure that none of the children had anaemia, parasites or infections at the time of the study.

All families signed the Free and Informed Consent Form and the study was approved by the Research Ethics Committee of the Federal University of São Paulo.

\section{Anthropometry}

The height and weight were obtained for each child in light clothing and stocking feet. Body weight was determined with an electronic scale (model SD-150; Country Technologies, Gay Mills, WI, USA) with a capacity of $150 \mathrm{~kg}$ and a precision of $100 \mathrm{~g}$. A standard stadiometer was used to determine the height of each child and the value closest to $0.1 \mathrm{~cm}$ was taken; each child stood against the vertical board of the stadiometer with arms hanging by the sides of the body and the head in the Frankfort plane. Weight-for-age (Z-score), height-for-age (Z-score), BMI $\left(\mathrm{kg} / \mathrm{m}^{2}\right)$ and BMI-for-age (Z-score) were calculated by the program EPI-INFO for Windows, using the National Center for Health Statistics reference (Centers for Disease Control, 2000).

\section{Pubertal stages}

The pubertal stage was evaluated by a trained physician using the Tanner classification (Tanner, 1962). The cut-off points recommended by the World Health Organization (1995) were used to classify the children into prepubertal or pubertal, that is, breast-stage 2 for girls and genitalia-stage 3 for boys.

\section{Biochemical analyses}

Plasma levels of glucose and specific insulin (without C-peptide) from the blood samples collected were determined by the colorimetric enzyme method (Bayer Inc., New York, USA) and the enzyme immunoassay method (TOSOH Inc., Tokyo, Japan) respectively.

The homeostasis model assessment (HOMA) model was used to evaluate pancreatic $\beta$-cell function and insulin sensitivity based on plasma and fasting levels of glucose and insulin. This technique uses a nonlinear mathematical model that reflects the balance between the glucose produced by the liver and basal insulin, maintained by a glucose-insulin feedback system between the liver and the pancreatic $\beta$-cells (Levy et al. 1998). The computer model is used to determine insulin sensitivity (HOMA-S) to the pancreatic $\beta$-cell function (HOMA-B) (Wallace et al. 2004).

Although the euglycaemic hyperinsulinaemic and the hyperglycaemic clamps are frequently referred to as the 'gold standard' methods for determining insulin resistance and pancreatic $\beta$-cell insulin production, the HOMA model, since its formulation (Wallace et al. 2004), has been validated by a number of studies that showed a good correlation between the estimates of insulin resistance and the euglycaemic clamp (Bonora et al. 2000), and between the estimates of $\beta$-cell function and the hyperglycaemic clamp (Matthews et al. 1985). Uwaifo et al. (2002) used the euglycaemic and hyperglycaemic clamps to validate the use of HOMA in well-nourished children. Gungor et al. (2004) validated the model in non-diabetic children and adolescents.

\section{Statistical analysis}

Separate analyses were made for boys and girls in order to test the differences between the group means. Analyses were done with the entire sample ( $n$ 61) and stratified by pubertal stage only for boys as only one girl of each group did not reach puberty.

The studied variables were age (years), group (stunted and non-stunted), gender (boys and girls), weight $(\mathrm{kg})$, height $(\mathrm{cm})$, weight-for-age (Z-score), height-for-age (Z-score), BMI $\left(\mathrm{kg} / \mathrm{cm}^{2}\right)$, BMI-for-age (Z-score), pubertal stage (pubertal and prepubertal), fasting glucose ( $\mathrm{mmol} / \mathrm{l})$ and insulin (pmol/ 1), and the calculated HOMA-B (\%) and HOMA-S (\%) indexes. The differences between the groups were tested with the Mann-Whitney test. Fisher's exact test was used to verify the differences in pubertal stage distribution between the groups.

The association of the HOMA-B and HOMA-S indexes with group was tested by multiple regression analysis for the entire sample (boys and girls), independent of pubertal stage and gender. The dependent HOMA-B and HOMA-S (in distinct models) variables were logarithmically transformed because they did not have a normal distribution. Pearson correlation coefficients between HOMA-B or HOMA-S and nutritional status variables were calculated in the children overall and including only pubertal children.

The analyses were performed with the software SPSS for Windows, version 11.0 (SPSS Inc., Chicago, IL, USA), with $\alpha=0.05$ for all the analyses.

\section{Results}

The characteristics of the children are presented in Table 1. Boys and girls in the stunted group showed values significantly lower for weight, height, weight-for-age and heightfor-age, but only the group of stunted boys showed significantly lower BMI and BMI-for-age values. The mean height-for-age was $<-2.0 \mathrm{Z}$-score for stunted boys and girls.

Table 2 shows the distribution of the children according to the pubertal stage classification. Half of the boys in the stunted group had not yet reached puberty while $35 \%$ of the boys in the non-stunted group were classified as pubertal, but the 
Table 1. Characteristics of the study children

\begin{tabular}{|c|c|c|c|c|c|c|c|c|c|c|}
\hline & \multicolumn{2}{|c|}{ Non-stunted } & \multicolumn{2}{|c|}{ Stunted } & $P$ & \multicolumn{2}{|c|}{ Non-stunted } & \multicolumn{2}{|c|}{ Stunted } & $P$ \\
\hline$n$ & 23 & & 12 & & & 17 & & 9 & & \\
\hline Age (years) & $11 \cdot 9$ & $2 \cdot 4$ & $13 \cdot 0$ & $1 \cdot 3$ & $0 \cdot 122$ & $13 \cdot 0$ & $1 \cdot 2$ & $13 \cdot 2$ & $1 \cdot 2$ & 0.525 \\
\hline Weight-for-age (Z-score) & 0 & 0.8 & -1.7 & 0.7 & $<0.001$ & -0.1 & 0.9 & -1.4 & 0.5 & $<0.001$ \\
\hline Height-for-age (Z-score) & 0.1 & 0.9 & $-2 \cdot 0$ & 0.7 & $<0.001$ & -0.3 & 0.8 & $-2 \cdot 1$ & 0.5 & $<0.001$ \\
\hline $\mathrm{BMI}\left(\mathrm{kg} / \mathrm{m}^{2}\right)$ & $18 \cdot 0$ & 1.7 & $16 \cdot 8$ & 1.9 & 0.049 & $19 \cdot 5$ & $3 \cdot 1$ & $17 \cdot 6$ & $2 \cdot 0$ & 0.095 \\
\hline BMI-for-age (Z-score) & 0 & 0.8 & -0.9 & 0.9 & 0.003 & 0.1 & 0.9 & -0.6 & 0.8 & 0.066 \\
\hline
\end{tabular}

difference in distribution was not significant. Among girls, only one child in each group had not yet reached puberty; there was no difference in distribution between the groups.

The results for the biochemical analyses are presented in Table 3. Stunted boys and girls showed similar values of plasma glucose, while the plasma insulin levels in these groups was significantly lower than those of the non-stunted group.

Fig. 1 describes the distribution of the HOMA-B and HOMA-S values in the two groups of boys and girls. When the entire sample was analysed, stunted boys and girls showed significantly lower HOMA-B (boys: 83 v. $115 \%$, $P=0.011$; girls: 107 v. $144 \%, P=0.045)$ at the same time that their values for HOMA-S were significantly greater (boys: 196 v. $120 \%, P=0.014$; girls: 159 v. $98 \%, P=0.016$ ).

When the analysis was stratified by pubertal stage, the difference between groups in HOMA-B and HOMA-S values was no longer significant for pubertal boys $(P=0.302$ and $P=0 \cdot 424$, respectively), while for prepubertal ones it remained significant in HOMA-S $(P=0.029)$ but not HOMA-B $(P=0 \cdot 081)$. Among pubertal girls, the difference in the HOMA-B values between the groups was marginally significant $(P=0.061)$ and the significance remained for the HOMA-S values $(P=0.016)$.

The association between group and the HOMA-B and HOMA-S indexes (after logarithmic transformation) was tested by multiple linear regression analysis, independent of gender and pubertal stage. In the two models tested (HOMA-B and HOMA-S as dependent variables), the regression coefficient of the group variable remained significant $(P=0.001)$ even after including gender and pubertal stage variables, with the $R^{2}$ values being equal to 0.35 and $0 \cdot 39$, respectively $(P<0.001$ in the two models).
The analyses of the relationship of the HOMA-B and HOMA-S indexes with the indicators of nutritional status for the children in the entire and pubertal children-only samples are described in Table 4. The HOMA-B index associates positively with weight-for-age, height-for-age, BMI and BMI-forage in both samples, the one including all the children and the one including only the pubertal children. On the other hand, the HOMA-S index is negatively associated with all the evaluated indicators of nutritional status, both for the entire and for the pubertal children-only samples. The Pearson correlation coefficient was highest in the relationship between the HOMA-B and HOMA-S indexes and BMI.

\section{Discussion}

The results of the present study show changes in insulin production and sensitivity in nutritionally stunted children. Specifically, stunted boys and girls showed lower fasting plasma insulin when compared to non-stunted children and there were no differences in plasma glucose levels between the groups. The calculated HOMA-B and HOMA-S indexes showed that stunted children have lower pancreatic $\beta$-cell function and higher insulin sensitivity when compared to non-stunted children.

The effect of puberty was controlled by multiple linear regression analysis and the group effect remained significant in the HOMA-B and HOMA-S indexes, regardless of gender and pubertal stage.

The HOMA model is a useful tool to estimate $\beta$-cell function and insulin sensitivity through simple measurements, such as insulin and glucose plasma levels, and has been validated by comparison with other models (Wallace et al. 2004). Yet, this is a qualitative index, so it is not possible to identify

Table 2. Pubertal stage distribution

\begin{tabular}{|c|c|c|c|c|c|c|c|c|c|c|}
\hline \multirow[b]{3}{*}{ Pubertal stage } & \multicolumn{4}{|c|}{ Boys } & \multirow[b]{3}{*}{$P$} & \multicolumn{5}{|c|}{ Girls } \\
\hline & \multicolumn{2}{|c|}{ Non-stunted } & \multicolumn{2}{|c|}{ Stunted } & & \multicolumn{2}{|c|}{ Non-stunted } & \multicolumn{2}{|c|}{ Stunted } & \multirow[b]{2}{*}{$P$} \\
\hline & $n$ & $\%$ & $n$ & $\%$ & & $n$ & $\%$ & $n$ & $\%$ & \\
\hline Pre-puberty & 8 & 35 & 6 & 50 & 0.387 & 1 & 6 & 1 & 11 & 0.582 \\
\hline Puberty & 15 & 65 & 6 & 50 & & 16 & 94 & 8 & 89 & \\
\hline
\end{tabular}


Table 3. Plasma glucose and insulin levels of stunted and non-stunted boys and girls*

\begin{tabular}{|c|c|c|c|c|c|c|c|c|c|c|}
\hline & \multicolumn{4}{|c|}{ Boys } & \multirow[b]{3}{*}{$P$} & \multicolumn{4}{|c|}{ Girls } & \multirow[b]{3}{*}{$P$} \\
\hline & \multicolumn{2}{|c|}{ Non-stunted } & \multicolumn{2}{|c|}{ Stunted } & & \multicolumn{2}{|c|}{ Non-stunted } & \multicolumn{2}{|c|}{ Stunted } & \\
\hline & Mean & SD & Mean & SD & & Mean & SD & Mean & SD & \\
\hline$n$ & 23 & & 12 & & & 17 & & 9 & & \\
\hline Glucose (mmol/l) & $4 \cdot 6$ & 0.3 & 4.5 & 0.2 & 0.294 & 4.4 & 0.3 & $4 \cdot 2$ & 0.3 & 0.107 \\
\hline Insulin (pmol/l) & $50 \cdot 4$ & $29 \cdot 1$ & $29 \cdot 7$ & 14.9 & 0.019 & $62 \cdot 3$ & $28 \cdot 7$ & 34.4 & $12 \cdot 6$ & 0.016 \\
\hline
\end{tabular}

${ }^{*}$ For details of procedures, see p. 997.

the mechanisms involved in the changes found in insulin sensitivity. The increase in insulin sensitivity may be due to a higher number of insulin peripheral receptors, especially in the adipose and muscle tissues. This increase in sensiti-
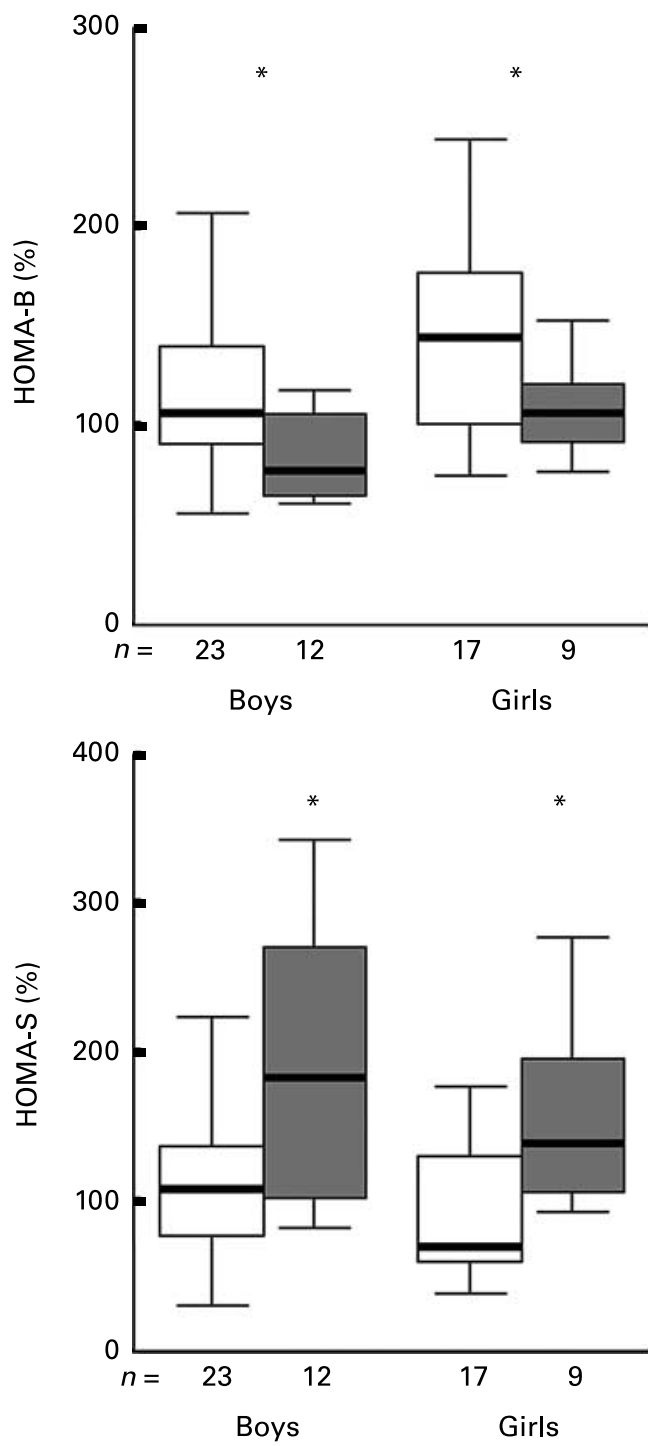

Fig. 1. Homeostasis model assessment for pancreatic $\beta$-cell function (HOMA-B) and for insulin sensitivity (HOMA-S) values of stunted ( $\square$ ) and non-stunted $(\square)$ boys and girls. For details of procedures, see p. 997. The box represents the interquartile range which contains $50 \%$ of the values, the vertical bars indicate the highest and lowest values (excluding outliers) and the line across the box indicates the median. Significant difference between groups: ${ }^{*} P<0.05$. vity may establish a counter-regulation mechanism to compensate for the low levels of insulin, which could have contributed to the preferential increase of fat with age observed in these children and described in a previous study (Martins et al. 2004).

According to our knowledge, this is the first time that a study shows a decrease in pancreatic $\beta$-cell function associated with an increase in insulin sensitivity in nutritionally stunted children by use of the HOMA index. In his review about protein-energy undernutrition and the resultant metabolic changes, Waterlow (1992) had already documented classic studies showing the occurrence of lower levels of plasma insulin, as well as hypoglycaemia, in severely undernourished children.

In the present study, the most likely explanation for the decrease in insulin production by the pancreatic $\beta$-cells is the presence of a lower number of cells due to undernutrition. As far as we know, the only data available are from intrauterine undernutition. By making a morphological analysis of the pancreas of fetuses presenting intrauterine growth retardation, Van Assche et al. (1977) observed a reduction in endocrine pancreatic tissue and insulin-producing $\beta$-cells. Recently, Holemans et al. (2003) described many studies involving man and animals with intrauterine undernutrition, where a lower secretion of insulin was associated with a delay in the development of pancreatic $\beta$-cells. Holemans et al. (2003) speculate that these changes could lead to an impaired adaptation of the pancreas to diets with higher glucose content and to insulin resistance in adult life. Cianfarani (2003) also suggested that intrauterine undernutrition would affect the number of stem cell precursors of pancreatic $\beta$-cells, which could lead to an early exhaustion of organ function, especially when the demand for insulin increases.

In the present study, besides a decrease in the HOMA-B index, we found an increase in insulin sensitivity in stunted children. Similar to what was observed in the present study, studies in animals observed a decrease in insulin secretion and an increase in the insulin-mediated total glucose uptake in rats that were subject to food restriction in early postnatal life (Picarel-Blanchot et al. 1995; Moura et al. 1996, 1997). Picarel-Blanchot et al. (1995) attributed their results to an adaptation that would limit the deterioration to glucose tolerance. Nevertheless, other studies showed that the insulin sensitivity pattern changes with age (Ozanne \& Hales, 2002). During the early phases of adult life, rats born to dams fed a low-protein diet showed better glucose tolerance when compared to a control group (Langley et al. 1994; Hales et al. 1996; Holness 1996). Yet, at 
Table 4. Pearson correlation coefficients between homeostasis model assessment for pancreatic $\beta$-cell function (HOMA-B) or for insulin sensitivity (HOMA-S) values and nutritional status variables, in the children overall and including pubertal children only*

\begin{tabular}{|c|c|c|c|c|c|c|c|c|}
\hline & \multicolumn{4}{|c|}{ Overall children ( $n 61)$} & \multicolumn{4}{|c|}{ Pubertal children ( $n$ 44) } \\
\hline & \multicolumn{2}{|c|}{ HOMA-B } & \multicolumn{2}{|c|}{ HOMA-S } & \multicolumn{2}{|c|}{ HOMA-B } & \multicolumn{2}{|c|}{ HOMA-S } \\
\hline & $R$ & $P$ & $R$ & $P$ & $R$ & $P$ & $R$ & $P$ \\
\hline Weight-for-age (Z-score) & 0.50 & $<0.001$ & -0.45 & $<0.001$ & 0.52 & $<0.001$ & -0.53 & $<0.001$ \\
\hline Height-for-age (Z-score) & 0.36 & 0.009 & -0.37 & 0.002 & 0.30 & 0.047 & -0.33 & 0.030 \\
\hline BMI-for-age ( $Z$-score) & 0.47 & $<0.001$ & -0.52 & $<0.001$ & 0.57 & $<0.001$ & -0.55 & $<0.001$ \\
\hline $\mathrm{BMI}\left(\mathrm{kg} / \mathrm{m}^{2}\right)$ & 0.63 & $<0.001$ & -0.54 & $<0.001$ & 0.63 & $<0.001$ & -0.59 & $<0.001$ \\
\hline
\end{tabular}

${ }^{*}$ For details of procedures, see p. 997.

44 weeks of age, the glucose tolerance was similar between the two groups (Petry et al. 1997) and at 15 months of age, the relationship inverted, with the protein-restricted group showing a lower glucose tolerance than the control group (Hales et al. 1996). At 17 months, diabetes mellitus was detected in these rats (Petry et al. 2001). Studies in isolated rat tissues suggested that these changes in sensitivity seem to be associated with variations in the number of insulin receptors (Ozanne et al. 1996, 2003).

The findings of the present study may be especially harmful to poor individuals living in urban areas and facing the challenges of the high glycaemic index of modern food types. Studies in adults with low birth weight have been showing a greater insulin resistance than normal individuals (Phillips, 1996; Lithell et al. 1996; Jaquet et al. 2000). A study in 20-year-old young adults who had a history of undernutrition in the first year of life showed that a larger amount of abdominal fat (measured by computerized tomography) was more detrimental to insulin sensitivity (evaluated by euglycaemic and hyperinsulinaemic clamp) to a higher degree than in individuals that had never been undernourished (Boule et al. 2003). Another study involving Indian children showed that the highest levels of insulin resistance were found in children who had a low birth weight and a higher fat mass at 8 years (Bavdekar et al. 1999). On the other hand, Moore et al. (2001) did not find changes in the glucose-insulin axis in individuals of the rural area of Gambia that were undernourished in childhood but remained lean in adult life.

The present study showed a decrease in pancreatic $\beta$-cell function and an increase in insulin sensitivity in children who have, as has previously been shown, increased body fat gain (Martins et al. 2004). In addition, the present findings on the metabolism of glucose and insulin may be involved in the metabolic changes that are responsible for the appearance of chronic diseases in adult life, such as obesity and type 2 diabetes. The large proportion of poor people living in urban areas underlines the importance of preventing stunting and therefore future non-communicable diseases later in life, in developing countries.

\section{References}

Bavdekar A, Yajnik CS, Fall CH, Bapat S, Pandit AN, Deshpande V, Bhave S, Kellingray SD \& Joglekar C (1999) Insulin resistance syndrome in 8-year-old Indian children: small at birth, big at 8 years, or both? Diabetes 48, 2422-2429.

Bonora E, Targher G, Alberiche M, Bonadonna RC, Saggiani F, Zenere MB, Monauni T \& Muggeo M (2000) Homeostasis model assessment closely mirrors the glucose clamp technique in the assessment of insulin sensitivity: studies in subjects with various degrees of glucose tolerance and insulin sensitivity. Diabetes Care 23, 57-63.

Boule NG, Tremblay A, Gonzalez-Barranco J, Aguilar-Salinas CA, Lopez-Alvarenga JC, Despres JP, Bouchard C, Gomez-Perez FJ, Castillo-Martinez L \& Rios-Torres JM (2003) Insulin resistance and abdominal adiposity in young men with documented malnutrition during the first year of life. Int $J$ Obes Relat Metab Disord 27, 598-604.

Centers for Disease Control (2000) CDC growth charts. http://www. cdc.gov/growthcharts/

Cianfarani S (2003) Foetal origins of adult diseases: just a matter of stem cell number? Med Hypotheses 61, 401-404.

Fernandes MT, Sesso R, Martins PA \& Sawaya AL (2003) Increased blood pressure in adolescents of low socioeconomic status with short stature. Pediatr Nephrol 18, 435-439.

Florêncio TT, Ferreira HS, Cavalcante JC, Luciano SM \& Sawaya AL (2003) Food consumed does not account for the higher prevalence of obesity among stunted adults in a very-low-income population in the Northeast of Brazil (Maceio, Alagoas). Eur J Clin Nutr 57, 1437-1446.

Florêncio TT, Ferreira HS, Cavalcante JC \& Sawaya AL (2004) Short stature, obesity and arterial hypertension in a very low income population in North-eastern Brazil. Nutr Metab Cardiovasc Dis 14, 26-33.

Florêncio TM, Ferreira HS, de Franca AP, Cavalcante JC \& Sawaya AL (2001) Obesity and undernutrition in a very-lowincome population in the city of Maceio, northeastern Brazil. Br J Nutr 86, 277-284.

Grillo LP, Siqueira AF, Silva AC, Martins PA, Vereschi IT \& Sawaya AL (2005) Lower resting metabolic rate and higher velocity of weight gain in a prospective study of stunted vs nonstunted girls living in the shantytowns of Sao Paulo, Brazil. Eur J Clin Nutr 59, $835-842$.

Gungor N, Saad R, Janosky J \& Arslanian S (2004) Validation of surrogate estimates of insulin sensitivity and insulin secretion in children and adolescents. J Pediatr 144, 47-55.

Hales CN, Desai M, Ozanne SE \& Crowther NJ (1996) Fishing in the stream of diabetes: from measuring insulin to the control of fetal organogenesis. Biochem Soc Trans 24, 341-350.

Hoffman DJ, Roberts SB, Verreschi I, Martins PA, de Nascimento C, Tucker KL \& Sawaya AL (2000a) Regulation of energy intake may be impaired in nutritionally stunted children from the shantytowns of Sao Paulo, Brazil. J Nutr 130, 2265-2270.

Hoffman DJ, Sawaya AL, Coward WA, Wright A, Martins PA, de Nascimento C, Tucker KL \& Roberts SB (2000b) Energy 
expenditure of stunted and nonstunted boys and girls living in the shantytowns of Sao Paulo, Brazil. Am J Clin Nutr 72, $1025-1031$.

Hoffman DJ, Sawaya AL, Verreschi I, Tucker KL \& Roberts SB $(2000 c)$ Why are nutritionally stunted children at increased risk of obesity? Studies of metabolic rate and fat oxidation in shantytown children from Sao Paulo, Brazil. Am J Clin Nutr $\mathbf{7 2}$ 702-707.

Holemans K, Aerts L \& Van Assche FA (2003) Lifetime consequences of abnormal fetal pancreatic development. J Physiol 15, $11-20$.

Holness MJ (1996) Impact of early growth retardation on glucoregulatory control and insulin action in mature rats. Am J Physiol $\mathbf{2 7 0}$ 946-954.

Jaquet D, Gaboriau A, Czernichow P \& Levy-Marchal C (2000) Insulin resistance early in adulthood in subjects born with intra-uterine growth retardation. J Clin Endocrinol Metab 85, 1401-1406.

Langley SC, Browne RF \& Jackson AA (1994) Altered glucose tolerance in rats exposed to maternal low protein diets in utero. Comp Biochem Physiol A Mol Integr Physiol 109, 223-229.

Levy JC, Matthews DR \& Hermans MP (1998) Correct homeostasis model assessment (HOMA) evaluation uses the computer program. Diabetes Care 21, 2191-2192.

Lithell HO, McKeigue PM, Berglund L, Mohsen R, Lithell UB \& Leon DA (1996) Relation of size at birth to non-insulin dependent diabetes and insulin concentrations in men aged 50-60 years. Br Med J 312, 406-410.

Martins PA, Hoffman DJ, Fernandes MT, Nascimento CR, Roberts SB, Sesso R \& Sawaya AL (2004) Stunted children gain less lean body mass and more fat mass than their non-stunted counterparts: a prospective study. Br J Nutr 92, 819-825.

Matthews DR, Hosker JP, Rudenski AS, Naylor BA, Treacher DF \& Turner RC (1985) Homeostasis model assessment: insulin resistance and beta-cell function from fasting plasma glucose and insulin concentrations in man. Diabetologia 28, 412-419.

Moore SE, Halsall I, Howarth D, Poskitt EM \& Prentice AM (2001) Glucose, insulin and lipid metabolism in rural Gambians exposed to early malnutrition. Diabet Med 18, 646-653.

Moura AS, Caldeira Filho JS, de Freitas MPC \& de Sá CC (1997) Insulin secretion impairment and insulin sensitivity improvement in adult rats undernourished during early lactation. Res Cоттип Mol Pathol Pharmacol 96, 179-192.

Moura AS, Carpinelli AR, Barbosa FB, Gravena C \& Mathias PC (1996) Undernutrition during early lactation as an alternative model to study the onset of diabetes mellitus type II. Res Commun Mol Pathol Pharmacol 92, 73-84.
Ozanne SE \& Hales CN (2002) Early programming of glucose-insulin metabolism. Trends Endocrinol Metab 13, 368-373.

Ozanne SE, Olsen GS, Hansen LL, Tingey KJ, Nave BT, Wang CL, Hartil K, Petry CJ, Buckley AJ \& Mosthaf-Seedorf L (2003) Early growth restriction leads to down regulation of protein kinase $\mathrm{C}$ zeta and insulin resistance in skeletal muscle. J Endocrinol 177, $235-241$

Ozanne SE, Wang CL, Coleman N \& Smith GD (1996) Altered muscle insulin sensitivity in the male offspring of protein-malnourished rats. Am J Physiol 271, 1128-1134.

Petry CJ, Dorling MW, Pawlak DB, Ozanne SE \& Hales CN (2001) Diabetes in old male offspring of rat dams fed a reduced protein diet. Int J Exp Diabetes Res 2, 139-143.

Petry CJ, Ozanne SE, Wang CL \& Hales CN (1997) Early protein restriction and obesity independently induce hypertension in 1-year-old rats. Clin Sci 93, 147-152.

Phillips DIW (1996) Insulin resistance as a programmed response to fetal undernutrition. Diabetologia 39, 1119-1122.

Picarel-Blanchot F, Alvarez C, Bailbe D, Pascual-Leone AM \& Portha B (1995) Changes in insulin action and insulin secretion in the rat after dietary restriction early in life: influence of food restriction versus low-protein food restriction. Metabolism 44, $1519-1526$.

Ravelli AC, van der Meulen JH, Michels RP, Osmond C, Barker DJ, Hales CN \& Bleker OP (1998) Glucose tolerance in adults after prenatal exposure to famine. Lancet 351, 173-177.

Tanner JM (1962) The development of the reproductive system. In Growth at Adolescence, 2nd ed. pp. 28-39. Oxford: Blackwell Scientific Publications.

Uwaifo GI, Fallon EM, Chin J, Elberg J, Parikh SJ \& Yanovski JÁ (2002) Indices of insulin action, disposal, and secretion derived from fasting samples and clamps in normal glucose-tolerant black and white children. Diabetes Care 25, 2081-2087.

Van Assche FA, de Prins F, Aerts L \& Verjans M (1977) The endocrine pancreas in small-for-dates infants. Br J Obstet Gynaecol 84, $751-753$

Wallace TM, Levy JC \& Matthews DR (2004) Use and abuse of HOMA modeling. Diabetes Care 27, 1487-1495.

Waterlow JC (1992) Protein-energy malnutrition: general introduction. In Protein Energy Malnutrition, pp. 1-13. London: Edward Arnold.

World Health Organization (1995) Physical Status: The Use and Interpretation of Anthropometry. Technical Report Series no. 854. Geneva: WHO.

Yajnik CS (2004) Early life origins of insulin resistance and type 2 diabetes in India and other Asian countries. J Nutr 134, 205-210. 